\title{
14. Discourse analysis as intervention: a case of organizational changing
}

Pascal Dey and Dörte Resch

\section{INTRODUCTION}

In recent years, researchers in management and organization studies have devoted considerable attention to discursive research, so it is hardly controversial to claim that discourse analysis is one of the field's most popular research methodologies. At the risk of simplifying, a key assumption underlying much of the available literature is that discourse analysis is primarily an excellent tool for producing knowledge (Heracleous, 2006) and more generally an analytic mentality (Phillips and Hardy, 2002). This interpretation is noteworthy as it consigns discourse analysis to its epistemological function.

Although we agree that discourse analysis is inextricably connected to questions of epistemology (knowledge), in this chapter we seek to transcend this position by demonstrating that it can also be used productively as a means of intervention. Conflating the epistemological and interventionist trajectories of discourse analysis, we build on prior work that conceives of 'method' and 'research' quite generally as a means for enacting and changing reality instead of 'only' representing or interpreting it (Law, 2004; Steyaert, 2011). Following this vein of thinking, we tentatively outline the interventionist potential of discourse analysis against the backdrop of organizational changing. Thereby, drawing on Tsoukas (2005), we define organizational changing as the process through which multiple discursive practices unfold, allowing members of organizations to give meaning to the organizational reality of which they are part. Using this approach, and analysing a consultancy project in a large German voluntary organization, we reveal how discourse analysis can be used to intervene in discursive practices that are characterized by tensions and struggle. To this end, we pinpoint how the results from one such analysis were used to break up a contracted conflict via two interrelated steps. First, discursive spaces were created that offered members of the organization an opportunity to vent their frustration and to create awareness of the 
antagonistic discursive practices that triggered the tensions and conflict. Second, generative dialogue allowed them to foster more affirmative re-interpretations of organizational changing.

This chapter is organized as follows. First, we advance a discursive understanding of organizational changing. Then, we offer an interventionist conceptualization of discourse analysis. In the third section we discuss the context, the case organization, and the design of the consultancy project. The fourth section offers a schematic outline of how discourse analysis was used to engage members of the case organization in new meaning-making practices by gradually shifting from 'talking tough' to a more generative mode of exchange. We draw the chapter to a close by identifying some areas for future research.

\section{FROM ORGANIZATIONAL CHANGE TO ORGANIZATIONAL CHANGING}

Organizational change is a central topic of Management and Organization Theory, and has been advanced from behavioural, cognitive and discursive perspectives (Tsoukas, 2005). At its simplest, a discursive perspective, which has risen to prominence over the last two decades (Heracleous and Barrett, 2001; Phillips and Oswick, 2012) emphasizes how discourses bring organizations and organizational phenomena into existence. In spite of the variety of interpretations of discourse, the notion of discourse mostly attends to how language works, not as a medium of representation but as an 'ordering force' of reality (Alvesson and Kärreman, 2000). Primarily concerned with the constitutive role of spoken and written language, discourse is commonly envisioned as the meaning-making practices which constitute the social reality which they ostensibly only describe. Discursive practices comprise such diverse phenomena as talk, text, metaphor, myth, narratives and images (Grant, Michelson, Oswick and Wailes, 2005).

Transposed to the topic of organizational change, a discursive perspective calls attention to how organizations are both constituted and changed via discursive practices. A discursive perspective sees organizational change less as a one-time, episodic event than as an ongoing process of discursively co-constructing meanings. As Hodge (2010, p. 34) points out, change 'is never final, but is always subject to changes, appearing and disappearing arbitrarily'. In line with research that sees organizational change as a process of 'becoming' and not as a 'momentary disturbance that must be stabilized and controlled' (Graetz and Smith, 2010, p. 136), Tsoukas (2005) suggests that we speak of 'organizational changing' instead of organizational change in order to stress the processual aspect of the 
phenomenon, the fact that it can never really be finalized. Embracing Tsoukas' conceptual twist, in this chapter, we speak of organizational changing to allude to instances where members of organizations invoke different and sometimes contradictory discourses to redefine, re-label, and reinterpret what happens within their organization, what their organization stands for, or what is considered to be its raison d'être (Jian, 2011). Organizational changing as an ongoing process of meaning-making thus encompasses the interweaving of different discourses, conceived as relatively coherent and (temporarily) stable patterns of meaning, which give rise to our experience of 'organization'.

\section{DISCOURSE ANALYSIS AS INTERVENTION}

It follows from the above that organizational changing involves tensions and struggle triggered by competing discourses. Tensions thus occur as certain discourses might reinforce the status quo of an organization, whereas others might transform established meanings. Although organizations rarely attain a state of complete discursive domination (or what Grant and Marshak (2011) call 'discursive closure') struggles do ensue over the question of who is given the opportunity to determine the 'what' and 'why' of organizational changing (Grant and Marshak, 2011). As organizational changing comprises competing discourses vying for dominance, the question, then, is how different, and often incompatible, discursive practices can be dealt with in ways that prevent open hostility, violence or deadlock. The managerial answer would be that managers must ensure the consent of their employees by making sure that they comply with and thus act according to the strategic desideratum of organizational cadres.

And yet, we are reluctant to accept that executives and managers are the only people in organizations who are entitled to 'destroy existing meaning systems and establish new ones in an effort to set strategic direction' (Sonenshein, 2010, p.477). Instead, envisioning organizational changing less as a hierarchical (that is, top-down) endeavour and more as a dialogic one (Marshak and Grant, 2008a), we contend that all members of an organization should be given the opportunity to participate in defining the 'what' and 'why' of organizational changing (Grant and Marshak, 2011). Granting all members an active role in the process of changing is in line with accounts which advocate that 'change recipients' (that is, ordinary employees) should also be granted voice in solving existing conflicts and in deciding on the organization's future direction (Ford, Ford and D'Amelio, 2008). The question that emerges here is how to best conceptualize such an inclusive prospect of organizational changing. 
It is here that discourse analysis has an important role to play. As a start, let us reiterate that discourse analysis can be productively used to intervene in (the making of) realities instead of merely representing reality (Law and Urry, 2005). Based on this premise, the overarching aim of discourse analysis as a vehicle for intervention is to engage members of the organization in generative dialogue (Scharmer, 2001) geared towards opening up less conflict-ridden, more affirmative ways of co-creating organizational reality. Such a shift towards generative dialogue fosters an openness to engage in a collective process of re-negotiating what the organization should stand for and how it should develop going forward. A crucial step towards generative dialogue is creating discursive spaces (Hardy and Maguire, 2010) where all members of a group, team or the organization at large can meet, describe their experiences and concerns, and learn to listen to other people's points of view. Whilst such encounters permit actors to exchange their dissenting viewpoints and gather a better understanding of how the struggles and tensions within their organization emanate from competing discourses, discourse analysis serves the purpose of making palpable the antagonistic discursive practices upon which a given organization is premised. Overall then, a crucial merit of discourse analysis is its ability to create minute insights into the ways that competing discourses spark tensions and conflict, which in turn can be fed back into a generative dialogue that gives all those in the organization a say in determining the purpose and prospect of organizational changing.

It is not difficult to see that the interventionist usage of discourse analysis involves an epistemological endeavour as a first step. That is, the results of a discourse analysis, which essentially reveal the different meaning-making practices that underpin a given organization, sensitize the organization's members about the 'open-ended micro-processes that' underlie 'the (changing) trajectories' (Tsoukas and Chia, 2002, p. 570). In other words, by making transparent how the breadth of meaning-making practices engenders tensions and conflicts (Grant and Marshak, 2011) discourse analysis allows all involved to understand that their organizations change in particular ways, experience turmoil and crisis, or become stagnant because of the specific discursive practices in which people engage (Thomas, Sargent and Hardy, 2011).

The actual intervention, then, is a matter of creating discursive spaces (Hardy and Maguire, 2010) to which all members of an organization have access and which do not privilege or exclude certain meanings and modes of speaking. Discursive spaces constitute democratic spaces which allow employees to freely express their 'truth', their vision of how things pertaining to the change-at-hand are or should be. The overarching aim of a discursive space is to provoke a generative dialogue geared towards the 'reweaving 
of actors' webs of beliefs and habits of action as a result of new experiences obtained through interactions' (Tsoukas and Chia, 2002, p. 570).

Before offering a vignette showing how we used discourse analysis as an interventionist tool, we first provide some background information on our empirical case material.

\section{CONTEXT}

This chapter had its beginning when our team, led by Annette Kluge, at the Research Institute for Organizational Psychology at the University of St. Gallen received an email invitation from one of the largest German voluntary organizations to partake in a tendering process. The focal attention of the organization, which we refer to using the pseudonym Subvenio, was, and still is, to support families and children in need. The project in question was resolving a protracted conflict which had become intense enough that the board of Subvenio sought external assistance. Two representatives of Subvenio visited us in St. Gallen to explain the mandate of the project and the conditions of the tendering process. During that meeting, it became obvious that the mandate was still very inchoate and that what the representatives told us strongly reflected their own interpretations of the reasons for the crisis at Subvenio.

In their view, the crisis was caused by the introduction of new managerial arrangements such as financial forecasting, budgeting, portfolio planning, and so on, which had estranged Subvenio's employees, because they ostensibly undermined values deeply entrenched in the organization such as spending time with and caring for their clientele. The new accounting systems took so much time to operate that people found it increasingly difficult to engage with others, be they colleagues or clients. By implication, the managerial arrangement had a direct negative effect on employees' ability to pursue the organization's social mission. Though Subvenio had overcome its precarious financial situation within less than two years, the struggles between the promoters of the reforms (read managers) and its sceptics had worsened as more and more employees raised their concerns over the value-disrupting effects of the new managerial arrangements.

Shortly after the initial contact, we were invited to come to the organization's headquarters in Germany to present our team to the two directors and select members of the board. On the sidelines of this gathering, the directors gave us a very different interpretation about the sources of the conflict at Subvenio. Although they agreed that the conflict was between management and employees, the directors did not frame the introduction of managerial tools and technologies as a sheer necessity in the face of 
looming financial misery. In their account, Subvenio had traditionally had little understanding of, and hence control over, its financial flows and expenditures, and that had led to a precarious financial situation caused by a slump in donations. Adhering to the idea that financial transactions at Subvenio had to be made more transparent, both directors were eventually dumbfounded by the amount of resistance their reforms produced among their employees.

Informal talks with members of the board revealed a third interpretation which occupied a middle ground between the two previous interpretations. Asserting that the managerial reforms were inevitable if Subvenio was to return to a sound financial foundation, members of the board maintained that the reforms jeopardized the organization's culture; in their view that made it crucial to engage in an open dialogue on issues related to values and tradition.

\section{METHODOLOGY: DESIGNING THE INTERVENTION}

Not long after our trip to Germany the board of directors notified us that they had given us the mandate, in large part because of our team's methodological expertise. Thus they granted us considerable liberties in designing the project and in choosing a methodology to address the hardened conflict at Subvenio. A steering committee, consisting of 12 volunteers (including both directors), was formed and given the task of serving as a 'sounding board' for our tentative ideas. Our basic thinking at the time was that the conflict was characteristic of those at many voluntary organizations that were pressured to become more businesslike (Maier, Meyer and Steinbereithner, 2014). In concrete terms, we believed that the incorporation of practices and instruments from the corporate realm was causing value-subverting effects (Eikenberry and Kluver, 2004) at Subvenio, also referred to as 'mission drift' (Minkoff and Powell, 2006). Framed in a discursive perspective, the conflict was due to discursive struggles triggered by competing discourses. Put bluntly, different groups at Subvenio promoted different interpretations of the managerial reforms, and different opinions on what the organization should be(come). Our working assumption was that the first step in getting a grip on the conflict would be identifying the various actors involved in shaping particular discourses, and pinpointing the extent to which these discourses clashed. Furthermore, our team was strongly convinced that to mitigate the conflict at Subvenio we would have to create opportunities where the quarreling parties could express their concerns and gradually shift from 'talking tough' to a more affirmative mode of collective meaning-making (Scharmer, 2001). 
The steering committee suggested framing the project as a 'cultural change' intervention; in their view, this term best resonated with the employees' perception of the conflict. We agreed to embrace the label, but insisted that we would use 'culture' as a proxy for 'discursive practice' (Alvesson, 2004). As we refused to see culture as a static property of Subvenio, 'culture' in our logic meant the heterogeneous discursive practices which ultimately engendered the conflict there. Stated this way, the main task going forward was to develop a design that would permit us to render palpable the ways that particular meanings were constructed in and through discursive practice (Wood and Kroger, 2000).

To this end, our team suggested various methods to illuminate the meaning-making practices at Subvenio. We presented a list of four methods to the steering committee. One was 'serious play' where people used Lego as a means for experimenting with organizational culture(s). The second was a 'force field' analysis which would represent the various forces affecting organizational culture(s) in either positive or negative ways. The third was the 'value square' which visualizes the tensions between different (cultural) values, and the fourth was the OCAI (Organization Culture Assessment Instrument; Cameron and Quinn, 1999), an empirically validated questionnaire representing four ideal-type profiles of specific cultural types: family/clan, hierarchy/bureaucracy, market, and adhocracy.

The OCAI was the only quantitative method. It had gained few adherents during the committee's previous discussions, but recurrent claims about the need to involve as many people as possible in the project and to create a more or less 'representative image' of Subvenio's cultural (read discursive) practices paved the way to use it across the organization. The OCAI was broadly promoted as the method of choice.

The steering committee agreed that the results of the OCAI should be used mainly to visualize Subvenio's different cultural practices. Most importantly, these visualizations should be fed back to the members of Subvenio during workshops in which at least one director would be present. In this way, the results of the OCAI formed the stimulus for the discursive spaces (Hardy and Maguire, 2010) to which all members of the organization were invited and which were presented as an opportunity to get together and exchange dissenting opinions and points of view. Apart from the results of the OCAI, which was completed by more than 400 people at Subvenio, we also gleaned valuable information from the innumerable corridor conversations and emails with people from different functional areas and hierarchical levels. Moreover, a source of surprisingly insightful information was the open question at the end of the OCAI where respondents were given the opportunity to post comments. They often gave lengthy descriptions of personal ordeals and other experiences, 
suggested ways to deal with the conflict, and offered both positive and negative appraisals of the worthiness of our project. Lastly, we chose to include in our analysis insights from formal meetings with Subvenio's managers and board of directors. These encounters provided insights into Subvenio's strategic considerations, offering important claims about how things were supposed to be done within the organization.

Subvenio's employees filled out the OCAI questionnaire online, but our analysis proceeded somewhat unconventionally. We had decided at the outset of the project that our team should not use any recording devices, to preclude the impression that we were simply pursuing our own (research) agenda, so we had to get by with taking notes and, most importantly, memorizing the formal and informal discussions, telephone conversations, and group discussions the three of us were involved in. Our analysis began right after the meetings and workshops at Subvenio; we used the long car rides back to St. Gallen from various German cities to make sense of our experiences.

In line with our own research (Dey, 2007; Resch, 2006), which was largely inspired by the discourse analysis developed by Potter and Wetherell (1987), we tried to rephrase our experiences at Subvenio in the language of interpretative repertoires: relatively stable sets of conversational schemas, or 'bounded units', built around specific terms (Wetherell and Potter, 1988, p. 172). By identifying the different interpretative repertoires which people invoked to make sense of what was going on in Subvenio, we were able to grasp the divergent logics circulating within the organization and potentially fuelling the conflict. Attempting to better understand how different actors used language to portray the purpose and prospect of Subvenio in particular ways, our attention focused on how to foster sensitivity for the competing discourses that had spurred the conflict (Buchanan and Dawson, 2007).

Our encounters with various people within the organization confirmed that employees and management held largely incompatible views about Subvenio's purpose and its future prospects. Once we were back in Switzerland, one of us checked our initial results against the backdrop of other available texts, and formalized the analysis in a Word document. This was followed by iterative discussions of the results between the two authors, the overarching aim being to corroborate our observations. The last step, then, consisted of the first author writing up the case narrative. The results of our analysis were transmitted via workshops which were set up either directly at Subvenio offices or in convention centres all across Germany.

Participants in the workshops were social workers, caretakers and administrators of various branch offices as well as a varying number of 
managers and board members. We began each workshop by presenting the results of our discourse analysis of the commentaries from the open questionnaire question, along with the corridor conversations, emails and formal meetings, as well as the results of the OCAI. In the section below, we first present the results of our discourse analysis and then, in a second step, outline how we used these insights to spark a generative dialogue between the quarrelling parties.

\section{COMPETING DISCOURSES: THE SOCIAL VERSUS MANAGERIAL REPERTOIRE}

Our discourse analysis revealed a myriad of meanings at play at Subvenio, but the discussion below is limited to the two competing discourses which had the greatest power in explaining the conflict at Subvenio: the social and the managerial repertoire.

\section{The Social Repertoire}

We chose the name social for the first interpretative repertoire. Summoned mainly by social workers and caretakers to hint at relational and axiological aspects of their work, the organization or its mission, the social repertoire is largely wedded to notions such as 'empathy, 'caring for others', 'companionship' and 'conviviality'. Importantly, the repertoire does not so much advance a descriptive account of the social reality of Subvenio. Rather, it provides a normative script delineating how things at Subvenio should be, ideally. This normative script about the social is established through a temporal division between, and juxtaposition of, Subvenio's 'golden past' (the time before the managerial reforms), its present (where the negative ramifications of the managerial reforms are plain for everyone to see) and its possible future (which essentially means a return to the cherished past).

Discussing the temporalities in turn, a first point worth noting is that the past of Subvenio, that is, the time before the funding gap, was portrayed in a unanimously positive light as the 'good old days' or the 'heydays' of Subvenio. Thus this repertoire conjures a nostalgic image of the past. This longing for the past results in large part from idealized portrayals of the organization's founder - we will call him Jakob Busch - who had passed away almost two decades earlier. In stories conveyed by employees, in brochures, and on the organization's homepage, and in images on display at Subvenio's premises, Busch is characterized as a genuinely 'compassionate', 'generous' and 'charismatic' individual, and as someone 
who 'cared more about others than about himself'. Often referred to as the 'father' of the organization, Busch is positioned by the repertoire as the originator of Subvenio's social outlook and culture. Thus, he is portrayed as both an extraordinary individual and a symbol of Subvenio's core values and culture 'back in the day'.

Clearly, the focus of the social repertoire is placed squarely on how Busch endowed Subvenio with a sense of purpose predicated on a common set of humanistic values. Busch is seen as a role model for Subvenio's values, which were still diffused through rituals and festivities which were presented as essential for cultivating solidarity among members of the organization.

The social repertoire suggests that in the past a particular emphasis was placed on beneficiaries - families and children in need - who were unanimously envisioned as the essence of Subvenio. Whilst beneficiaries ostensibly used to be at the very centre of Subvenio, accounts of the past further stress that employees were then treated by both their superiors and their colleagues not as means to certain ends but as ends in themselves. 'Respect', 'authentic trust' and 'informality' were mentioned as key features of the way that employees, their direct superiors and Busch himself, as well as his immediate successor, interacted in the past. A key contention in accounts of the past is that all people at Subvenio, regardless of their status, function and role, were treated with dignity and respected as human beings.

This ideal situation is contrasted with the sombre presence of Subvenio. The current disenchantment is attributed directly to the managerial reforms which ostensibly weakened the bonds among employees, as well as between employees and beneficiaries. As we mentioned earlier, people challenged the managerial reforms because they saw them as diverting both time and money away from the organization's social mission. A decisive point in this argument is that these reforms have transformed Subvenio from a family-oriented and solidarity-based organization to one mainly concerned with financial forecasting and budgeting. This shift towards valuing managerial prowess was presented as an extremely problematic caesura of Subvenio which threatened to marginalize its cultural heritage and core values. The push towards managerialism was causally linked to the two current directors whose appointment coincided with Subvenio's precarious financial performance at that time. This explanation of the crisis that followed the reforms made the two directors appear as 'culprits' who bore responsibility for the nuisances the employees were experiencing.

In turn, accounts of Subvenio's future indicated how to deal with the current impasse and how to go forward. Accounts of its future were largely concerned with re-establishing the situation that existed before the 
reforms. Paradoxically, the quest towards the future eventually formed a backwards-oriented gesture. This longing to return to a bygone era was expressed, for example, by a caretaker who claimed that "the "real work" with the residents should again be appreciated more and employees should be adequately supported'. Further, 'we must stop focusing too much on our own (economic well-being) as well as the pressures engendered by the newly introduced entrepreneurial language and thinking'. This quote is indicative of how the social repertoire eulogizes the past by pinpointing its myriad of merits. Presenting the managerial reforms as posing a threat to Subvenio's core values and social mission, the social repertoire essentially marks an attempt to re-establish the pre-eminence of social workers and caretakers (over managers) by stressing that they are ultimately the ones working 'at the frontiers of Subvenio's social services'. Further, the social repertoire demands that more time should be reserved for working with Subvenio's beneficiaries who, as the same caretaker maintained, are the ones 'who really count'.

\section{The Managerial Repertoire}

In contrast, the managerial repertoire was used almost exclusively by the two directors and by select members of the board. In sharp contrast to the social repertoire, the managerial repertoire represents the managerial reforms as unalterable and rational, and as being in the best interest of the organization. A persistent theme of this repertoire is that the reforms were instrumental in improving Subvenio's performance and, most importantly, in ensuring it would survive. Relating the reforms to efficiency and performance, the main emphasis of the managerial repertoire is on how the reforms noticeably increased Subvenio's ability to plan and control its activities based on financial information. In this way, the managerial repertoire chiefly echoes the now widespread belief that practices from the private sector have great potential for making voluntary organizations more sustainable and financially self-sufficient (Maier et al., 2014).

Thus the discursive justification of the managerial reforms at Subvenio is predicated on two distinct registers: pragmatism and urgency. Specifically, those using this repertoire hold that the reforms are pragmatic as they offer an efficient, objective and rational solution to the financial turmoil Subvenio had witnessed some years earlier. Central to the conception of management reforms as pragmatic is the belief that given the right management techniques, it should be possible to eliminate the current frictions and troubles (Morozov, 2013). And yet, in signifying managerial reforms as pragmatic, the managerial repertoire glosses over the fact that such interventions do not necessarily offer a value-free approach to organizational 
changing, since changing always has to do with contesting and negotiating values, interests and, potentially, relations of power.

The second justificatory regime conjures a sense of urgency by framing the managerial reforms at Subvenio as 'necessary', 'inevitable' and 'indispensable'. Underlying this justification is the assumption that Subvenio had no other option but to implement the reforms - that it could not have survived without them. This invites the conclusion that the managerial repertoire establishes a 'do-or-die' mentality by highlighting that refusing to implement the reforms would have irrevocably led to Subvenio's demise.

\section{FROM TALKING TOUGH TO LISTENING CLOSELY}

After they had listened to the presentation about the two repertoires, the workshop participants were divided into groups and asked to discuss and comment on what they had just heard. The groups were set up to facilitate encounters between people who did not work in the same area or team, and would rarely meet while at work. Participants were assured that they could speak openly about things at Subvenio that concerned or upset them without having to fear any negative consequences.

By and large, our general impression was that workshop participants had little difficulty in relating to and making sense of the results of our discourse analysis. During the early stages of the discussion we noted a tendency amongst participants to merely reproduce the two repertoires. That is, they often affirmed that their preferred repertoire was correct and legitimate, and denigrated the value of the rival position. To simplify somewhat, we noted that social workers and caretakers stressed that the social mission and values formed the centrepiece of Subvenio, and that the reforms created a major obstacle to realizing that mission. Managers, on the other hand, maintained that Subvenio's social mission had been jeopardized precisely because it had lacked proper mechanisms to steer and control its finances. Managers thus contended that there was no way around becoming more business savvy, whatever the temporary repercussions such a shift might cause.

What we can see here is that the rival parties enacted the two repertoires as irreconcilable. The early stage of the dialogue was underpinned by a zero-sum logic: the belief that one party's gain would inextricably lead to a loss by the opponent. The exchanges between the two groups - the managers, and the social workers and caretakers - were in fact polarized, reactive and at times even hostile. Still, we remained mindful that it was imperative for the participants to experience such a moment of 'talking tough' (Scharmer, 2001), using the two discourses which had 
caused the conflict in the first place. At the same time, though, it was clear that a dialogue premised on 'talking tough' was insufficient to overcome the conflict because it obstructed any appreciation of the other party's perspective.

Hence, we saw the need to gradually shift the perspective of the dialogue so participants could move to a more affirmative and constructive mode of exchange. So, after they had expressed their viewpoints and worries, and vented their frustrations, our team instructed them to temporarily suspend judgement and to pay close attention to what their 'opponents' actually had to say. Listening closely to the perspective of the others had a distinct effect: It redirected their attention so they could see the situation at Subvenio through the eyes of their counterparty.

To help each group foster a proper appreciation for the perspective adopted by their opponents, our team tried to shift their perception of the conflict at Subvenio by moving their focus. Instead of focusing solely on the people (that is, managers, caretakers, social workers) who invoked the respective repertoires, we suggested they see the repertoires as tightly related to the organizational roles and responsibilities bestowed upon these people. Making it clear that the two repertoires chiefly reflected people's positions and functions within the organization rather than their private proclivities and interests, we also drew on existing research to underscore that managers of voluntary organizations typically emphasize issues related to strategy, mission and organizational purpose whereas employees tend to focus more on cultural issues, including values and practices. Our aim with this instruction was to de-individualize the conflict at Subvenio by helping them all see that any individual's appraisal of the two repertoires would be a function of their own position.

Moving against the tendency to appraise the two repertoires as either 'black or white', we acquainted the participants with the idea that any attempt to judge the opposing repertoire would be incomplete unless they also considered the roles, duties, practical constraints and goals associated with the perspective of the other. Once we created a heightened acceptance of the opponent's point of view and a better awareness of the organizational position from which each side enunciated its repertoire, we were then able to move away from gridlocked interpretations of the two repertoires, and towards generative dialogue where both sides could sense and actualize new possibilities (Jaworksi and Scharmer, 2000). 


\section{GENERATIVE DIALOGUE AND THE RENEGOTIATION OF MEANING}

A key insight transmitted during the various workshops was that the two repertoires which had triggered the conflict at Subvenio were contingent and thus could be changed. This revelation was crucial for nudging changes in individuals' casual way of making sense of their organizational reality (Brown and Humphreys, 2003). To allow them to tap new ways of making sense of the 'what' and 'why' of organizational changing (Grant and Marshak, 2011), we then asked them to analyse closely which aspects of the two repertoires were supporting or hindering their everyday work in specific and their sense of purpose and commitment more generally. We then divided them into small groups and instructed them to share their individual appraisals with their colleagues and try to establish, via extended discussions, a tentative consensus around which aspects of the two repertoires should be retained and which ones should be changed.

We also called on them on to treat the inputs of their colleagues with respect. And we stressed that they should try to engage as constructively as possible with the rival repertoire by trying to understand it in detail and redefine it instead of merely rejecting it. This instruction mostly fell on fertile ground: The caretakers and social workers readily elaborated how the managerial repertoire could be altered to better fit their everyday realities, whilst managers reflected on ways the social repertoire could be adapted to minimize frictions with the newly implemented accounting systems. The outcomes of the group discussions were captured on flip charts and later presented in a plenary session. Table 14.1 reproduces one such flip chart, recorded as a group evaluated the two repertories in terms of their respective advantages (the dimensions 'to be sustained') and disadvantages (the dimensions 'to be changed').

A striking observation was that, after some brief hesitations, both employees and managers increasingly shifted from defending their preferred repertoire to engaging in generative dialogue that led to new interpretations of both repertories. Flexibly removing aspects of the two repertoires whilst adding others, the participants gradually transformed the two repertoires based on the insights and experiences gathered during the group conversations. In this way, generative dialogue permitted groups to re-imagine what Subvenio stands for in largely novel ways. The generative dialogue had a pacifying effect as it dissolved the antagonism between the two interpretative repertoires. The tensions between the two groups were reconciled as the intervention changed the two repertoires, thereby disrupting the strict correspondence between group and repertoire, that is between the social repertoire and the social workers and caretakers and, 
Table 14.1 Example of a generative dialogue at Subvenio

\begin{tabular}{lcccc}
\hline Social & \multicolumn{3}{l}{ Managerial } \\
\cline { 1 - 2 } To be sustained & To be changed & & To be sustained & To be changed \\
\hline- Humour & - 24-hour & - Power & - & The weak and \\
- Lived values & availability & - Responsibility & vulnerable \\
- Emphasis on & - 'We are all & and & have no right \\
relations & nice with & accountability & to exist \\
- Valuing the & each other' & - External per- & - People are \\
individual & climate & ception in terms & positioned as \\
- Tolerance of failures & - Inability to & of efficiency & inferior once \\
- Patience & perform vis- & - Competitiveness & they are not \\
- Inclusiveness & à-vis donors & - Goal orientation & able to trigger \\
- Relevance to the & & & their full \\
identity of Subvenio & & & potential \\
\hline
\end{tabular}

on the other hand, between the managerial repertoire and the managers. It became clear that engaging organizational members in generative dialogue had the distinct effect of dissolving the root of the conflict: the competing discourses.

Cursory though this discussion has been, the key insight to be gleaned from our consultancy project is that organizational changing, to be successful, presupposes a thoroughgoing dialogue between managers and employees where competing discourses are interpreted and further reinterpreted by those' they address, 'depending on the interpretative codes and the local circumstances of its addressees' (Tsoukas and Chia, 2002, pp. 579-580). Such iterative interpretations eventually change antagonistic discursive practices and allow rival parties to incrementally experience each other as 'allies' in a quest towards redefining the purpose and prospect of organizational changing.

\section{CONCLUDING DISCUSSION}

Traditional accounts of discourse analysis conceive of the subject matter more or less exclusively as an epistemological tool - that is, a tool for studying how meaning is created through language (Wood and Kroger, 2000). In contrast, our central contention in this chapter has been that discourse analysis can serve as a means to intervene in the ways that organizational reality is created and changed. Based on a consultancy project at Subvenio, one of the largest German voluntary organizations, we have explored the 
interventionist possibilities of discourse analysis by attending to how it can be employed to steer organizational members towards a more affirmative mode of exchange. Perhaps this work's most important contribution is showing that discourse analysis does in fact have practical value (Oswick, Grant, Marshak and Cox, 2010).

Discourse analysis has practical value to the extent to which it works to engage people in generative dialogue (Gee, 2005) so it instigates movement where tensions and conflict had prevailed. By fostering generative dialogue amongst members of an organization, an interventionist usage of discourse analysis suggests that those people move from talking tough to actively participating in the process of organizational changing. Hence, what is crucially at stake in an interventionist usage of discourse analysis is the question of how competing discourses within an organization can be made palpable for all involved, and how, in turn, people can learn to re-evaluate these discourses with an eye towards suspending organizational conflicts.

To be sure, any consulting team needs to remain impartial with regard to defining the 'what' and 'why' of organizational changing (Grant and Marshak, 2011). Although impartiality can prove difficult to sustain in practice, as one might develop sympathies for some discourses more than for others, impartiality nevertheless becomes an indispensible part of any intervention that tries to confront competing discourses in largely affirmative ways. In this light, a central merit of an interventionist usage of discourse analysis is precisely that it fosters impartiality by supporting those involved in cultivating a more inclusive way of interpreting organizational reality that relaxes antagonistic discursive practices. In saying this, of course, we do not suggest that certain voices and interests might remain more authoritative than others in shaping an organization's trajectory and purpose (Tsoukas and Chia, 2002). It remains true that power will always play a role in determining who can speak and who is heard in the context of organizational changing (Marshak and Grant, 2008b), but in this chapter we have tried to raise awareness that generative dialogue has great potential to prevent an existing discourse from becoming dominant by rendering organizational changing democratic and non-hierarchical.

Our objective was to show how existing relations of power at Subvenio were temporarily neutralized through the process of establishing discursive spaces that were bracketed away from everyday action, and that offered the possibility of creating alternative interpretations that could, in turn, alter the general outlook of the organization (Howard-Grenville, GoldenBiddle, Irwin and Mao, 2011). Thus our intervention at Subvenio helped keep the influence of existing hierarchies and relations of power in check by ensuring that none of the discourses were excluded or marginalized 
(Deetz, 1992). We believe our intervention had a positive effect at Subvenio, at least during the time we were active there, because people we spoke to readily acknowledged that moving the organization out of its crisis presupposed that everyone would adopt a 'democratic spirit' (Eisenberg, 1994). Conceding that it made little sense to view managers as the only legitimate 'change agents' in the organization (Sonenshein, 2010), board members in particular encouraged our team to overcome the existing hierarchies, thereby placing managers and employees on a level playing field. Using workshops as a contact zone where opposing vistas and interests could meet proved helpful for curbing partisanship, fostering sympathy with opposing views and, most significantly, allowing for alternative visions of Subvenio to materialize.

Whilst this work casts a positive light on the interventionist potential of discourse analysis, we must also bear in mind that discourse analysis plays a marginal role in 'real-life' consultancy projects dealing with organizational changing. Indeed, while we were preparing this chapter, we simply could not find published guidance on analysing discursive practices that have not been tape-recorded. Whereas scholarly texts on discourse analysis mostly stipulate methodological techniques ('first this, then that') and standards of quality and rigor, these discussions, although significant in their own right, have very little practical significance for projects in which the consultants cannot record and transcribe conversations and interviews. To address this lacuna, we believe that future researchers should attune discourse analysis to the particular needs and conditions of (consulting) practice.

Thus we see a particularly urgent need: to address in sufficient depth the ways that discourse analysis can support consultants in implementing organizational changing in a more participatory and democratic way. Moreover, we deem it important to establish analytic conventions and principles for dealing with non-recorded discursive practices (Hammersley, 2005). If researchers and practitioners accept that an interventionist approach to discourse analysis enacts reality in largely new ways (Grant and Iedema, 2005), then it may be possible to use whatever kind of data are available to complete a given task. We have tried to take a first step in this direction by opening up discourse analysis to sources of information which typically exceed the scope of textbooks on discourse analysis. We are well aware that this task is far from completed, and that the interventionist usage of discourse analysis can be extended in several directions. At this decisive point in time, we are curious to see if and how others relate to this debate and move it forward. 


\section{REFERENCES}

Alvesson, Mats (2004), 'Organizational culture and discourse', in David Grant, Cynthia Hardy, Cliff Oswick, and Linda L. Putnam (eds), The Sage Handbook of Organizational Discourse, London: Sage, pp. 317-335.

Alvesson, Mats and Dan Kärreman (2000), 'Varieties of discourse: On the study of organizations through discourse analysis', Human Relations, 53 (9), 1125-1149.

Brown, Andrew D. and Michael Humphreys (2003), 'Epics and tragic tales. Making sense of change', Journal of Applied Behavioral Science, 39 (2), 121-144.

Buchanan, David and Patrick Dawson (2007), 'Discourse and audience: Organizational change as a multi-story process', Journal of Management Studies, 44 (5), 669-686.

Cameron, Kim S. and Robert E. Quinn (1999), Diagnosing and Changing Organizational Culture, Reading, MA: Addison-Wesley.

Deetz, Stanley A. (1992), Democracy in an Age of Corporate Colonization: Developments in Communication and the Politics of Everyday Life, New York: State University of New York Press.

Dey, Pascal (2007), On the Name of Social Entrepreneurship: Business School Teaching, Research, and Development Aid, unpublished doctoral dissertation, Basel, Switzerland: University of Basel.

Eikenberry, Angela M. and Jodie D. Kluver (2004), 'The marketization of the nonprofit sector: Civil society at risk?', Public Administration Review, 64 (2), 132-140.

Eisenberg, Eric M. (1994), 'Dialogue as democratic discourse: Affirming Harrison', in Stanley A. Deetz (ed.), Communication Yearbook 17, Thousand Oaks, CA: Sage, pp. 275-284.

Ford, Jeffrey D., Laurie W. Ford and Angelo D'Amelio (2008), 'Resistance to change: The rest of the story', Academy of Management Review, 33 (2), 362-377.

Gee, James P. (2005), An Introduction to Discourse Analysis: Theory and Method, New York: Routledge.

Graetz, Fiona and Aaron C.T. Smith (2010), 'Managing organizational change: A philosophies of change approach', Journal of Change Management, 10 (2), 135-154.

Grant, David and Rick Iedema (2005), 'Discourse analysis and the study of organizations', Text: An Interdisciplinary Journal for the Study of Discourse, 25 (1), $37-66$.

Grant, David and Robert J. Marshak (2011), 'Toward a discourse-centered understanding of organizational change', The Journal of Applied Behavioral Science, 47 (2), 204-235.

Grant, David, Grant Michelson, Cliff Oswick and Nick Wailes (2005), 'Guest editorial: Discourse and organizational change', Journal of Organizational Change Management, 18 (1), 6-15.

Hammersley, Martyn (2005), 'Ethnography and discourse analysis: Incompatible or complementary?', Polifonia, 10, 1-20.

Hardy, Cynthia and Steve Maguire (2010), 'Discourse, field-configuring events, and change in organizations and institutional fields: Narratives of DDT and the Stockholm Convention', Academy of Management Journal, 53 (6), 1365-1392.

Heracleous, Loizos T. (2006), 'Images of discourse: Interpretive, functional, 
critical and structurational', in Loizos Heracleous (ed.), Discourse, Interpretation, Organization, Cambridge: Cambridge University Press, pp. 1-27.

Heracleous, Loizos T. and Michael Barrett (2001), 'Organizational change as discourse: Communicative actions and deep structures in the context of information technology implementation', Academy of Management Journal, 44 (4), 755-778.

Hodge, Bob (2010), 'Oedipus and the CEO: Ambiguities of change in myth, discourse and practice', Culture and Organization, 16 (1), 23-35.

Howard-Grenville, Jennifer, Karen Golden-Biddle, Jennifer Irwin and Jina Mao (2011), 'Liminality as cultural process for cultural change', Organization Science, $22(2), 522-539$.

Jaworski, Joseph and Claus O. Scharmer (2000), 'Leadership in the new economy: Sensing and actualizing emerging futures', working paper, Society for Organizational Learning, Cambridge, MA.

Jian, Guowei (2011), 'Articulating circumstance, identity and practice: Toward a discursive framework of organizational change', Organization, 18 (1), 45-64.

Law, John (2004), After Method: Mess in Social Science Research, New York: Routledge.

Law, John and John Urry (2005), 'Enacting the social', Economy and Society, 33 (3), 390-410.

Maier, Florentine, Michael Meyer and Martin Steinbereithner (2014), 'Nonprofit organization becoming business-like: A systematic review', Nonprofit and Voluntary Sector Quarterly (online first).

Marshak, Robert J. and David Grant (2008a), 'Organizational discourse and new organization development practices', British Journal of Management, 19 (1), 7-19.

Marshak, Robert J. and David Grant (2008b), 'Transforming talk: The interplay of discourse, power, and change', Organization Development Journal, 26 (3), 33-40.

Minkoff, Debra C. and Walter W. Powell (2006), 'Nonprofit mission: Constancy, responsiveness, or deflection?', in Walter W. Powell and Richard Steinberg (eds), The Nonprofit Sector: A Research Handbook, New Haven, CT: Yale University Press, pp. 591-611.

Morozov, Evgeny (2013), To Save Everything, Click Here: Technology, Solutionism, and the Urge to Fix Problems that Don't Exist, London: Allen Lane.

Oswick, Cliff, David Grant, Robert J. Marshak and Julie W. Cox (2010), 'Organizational discourse and change: Positions, perspectives, progress, and prospects', The Journal of Applied Behavioral Science, 46 (1), 8-15.

Phillips, Nelson and Cynthia Hardy (2002), Discourse Analysis: Investigating Processes of Social Construction, Thousand Oaks, CA: Sage.

Phillips, Nelson and Cliff Oswick (2012), 'Organizational discourse: Domains, debates, and directions', Academy of Management Annals, 6 (1), 435-481.

Potter, Jonathan and Margaret Wetherell (1987), Discourse and Social Psychology, London: Sage.

Resch, Dörte (2006), Soziales Miteinander in Organisationen - Diskurse und Funktionen zwischen individueller Kompetenz und organisationaler Metapher, unpublished doctoral dissertation, Neuchâtel, Switzerland: University of Neuchatel.

Scharmer, Claus O. (2001), 'Self-transcending knowledge: Sensing and organizing around emerging opportunities', Journal of Knowledge Management, 5 (2), $137-150$. 
Sonenshein, Scott (2010), 'We're changing - or are we? Untangling the role of progressive, regressive, and stability narratives during strategic change implementation', Academy of Management Journal, 53 (3), 477-512.

Steyaert, Chris (2011), 'Entrepreneurship as in(ter)vention: Reconsidering the conceptual politics of method in entrepreneurship studies', Entrepreneurship \& Regional Development, 23 (1), 77-88.

Thomas, Robyn, Leisa D. Sargent and Cynthia Hardy (2011), 'Managing organizational change: Negotiating meaning and power-resistance relations', Organization Science, 22 (1), 22-41.

Tsoukas, Haridimos (2005), 'Afterword: Why language matters in the analysis of organizational change', Journal of Organizational Change Management, 18 (1), 96-104.

Tsoukas, Haridimos and Robert Chia (2002), 'On organizational becoming: Rethinking organizational change', Organization Science, 13 (5), 567-582.

Wetherell, Margaret and Jonathan Potter (1988), 'Discourse analysis and the identification of interpretative repertoires', in Charles Antaki (ed.), Analysing Everyday Explanation: A Casebook of Methods, Newbury Park, CA: Sage, pp. $168-183$.

Wood, Linda A. and Rolf O. Kroger (2000), Doing Discourse Analysis. Methods for Studying Action in Talk and Text, Thousand Oaks, CA: Sage. 